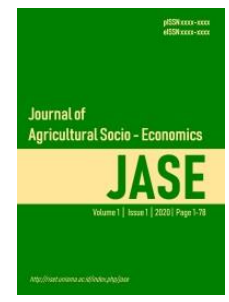

\title{
Socio-Economic Factors Affecting Agricultural Production and Income in Bangladesh
}

\author{
Susmita Das ${ }^{1 *}$, Paritosh Mondal ${ }^{2}$ \\ ${ }^{1}$ Bangladesh Agricultural Council, Dhaka 2015, Bangladesh \\ ${ }^{2}$ Gazaria Government College, Munshigonj, Bangladesh \\ *E-mail: susmitabarc@gmail.com
}

\begin{abstract}
The study assessed some factors that determine agricultural production and income in Bangladesh. The factors that were addressed in the study were land, labour, capital, ethnicity, gender etc. It aimed to analyze the socio-economic characteristics of the farmers in Bangladesh, to investigate the level of agricultural production activities and to identify the agricultural production problems in Bangladesh. The target population was the farmers of eight divisions in Bangladesh. The data were obtained from structured questionnaires, semi-structured interviews and FGD. Multiple linear regression of model fourteen explanatory variables was used to analyze the characteristics of the factors mentioned above in context of farm production and income. The result of data analysis showed that the variables such as gender, age, years of schooling, service area, operational farm size, cow-shed, electricity, radio, mobile phone, television, computer, bicycle, motorcycle etc. affect farmers' production and income. The research also found gender parity and small farm holding in farming. There should be provision of effective agricultural information dissemination services by using ICT tools in farming. Special emphasis should be given to eliminate gender disparity and resolve small farm holding problem to ensure farm production and income generation.
\end{abstract}

Keywords: social factors; production; income; multiple linear regression model

\section{INTRODUCTION}

Agriculture is the backbone of economy in Bangladesh. Now it is the catalyst for the fastest growth and poverty reduction as the right policies are developed and implemented with the right institutional framework (Das, 2016). Agriculture contributes to around 15.96\% (FY 2014-2015) (BBS, 2015) of the country's Gross Domestic Product (GDP) and generates employment for 45 percent of the total labor force (BBS, 2015). Increasing agricultural production for growing people is a major challenge for present agriculture. It has generated much of the country's export earnings. Yet agriculture in Bangladesh has been faced with some natural, social, economic and political factors that affect farming to some extent. The factors that directly affect agriculture and its income are land, labour, capital, ethnicity, gender etc. Social factors through different phenomena like tribal culture, gender bias attitude, family type and trend, cultural hegemony appear to be omnipresent in the mainstream like agriculture (Barbieri and Mahoney, 2009). The present study aims to identify some determinants that affect farming income in a number of ways. These determinants influence shifting cultivation, subsistence farming, and mixed farming. These factors also affect the type of crops that are grown.

Fertility of soil is important. Poor soil means lower outputs or larger inputs of fertilizers. Much of the soil is floodplain and it is good for rice because of the alluvium. Land is an important factor that influences the totality of agriculture and brings about fluctuations in the production. In Bangladesh, soil is fertile but land is fragmented due to the result of social norms and family trends. The total land area of Bangladesh is about 14.3 million hectares of which about $59.8 \%$ is available for cultivation (Islam, 2003). About 8.0 million net land are available for cultivation with cropping intensity of $191 \%$ (meaning one unit area of land used for different crops). The production system in Bangladesh is smallholder 
dominated with an average farm size of 0.6 hectares (BBS, 2009). Farm size is determined by farmers' socioeconomic factors that influence their livelihood and agro-diversity. Though farm size varies from area to area and a certain measurement determines the classifications of farmers with their farm size. There are five categories of farm size in Bangladesh 1) Landless 0.00-0.49 Acre, 2) Marginal 0.50-1.49 Acre, 3) Small 1.50 to 2.49 Acre, 4) Medium 2.50 to 7.49 Acre and 5) Large 7.50- above Acre (BBS, 1996). In Bangladesh, small \& marginal farmers dominate all other groups. Social norm and structure is responsible for the fragmentation of cultivable land. The small and marginal farms are more than any other category. The table 1 shows that $40 \%$ of the total respondents belong to small farming. The number of large farmers is considerably less $(1 \%)$. The second highest is marginal farmers $(46 \%)$. The landless category consists of 5\% farmers. The rest is in the medium group (8\%). The fact remains that the farm size has been diminishing as a result of fragmentation and also because contact farming is yet to be developed. Besides, agricultural land declined by $0.26 \%$ per year between 1976 and 2010, including an acceleration to $0.45 \%$ per year between 2000 and 2010 (Hassan et al., 2013).

Labour is another factor that greatly affects farming and determines the production costs. In Bangladesh, farmers use abundant cheap labour instead of machines, but in developed countries like Japan and the UK, labour is expensive, they use machines (Bruckner, LaFleur, \& Pitterle, 2017). People working on farms may be unskilled labourers or skilled and able to use machinery, e.g. tractors, harvesters and milking machines. Owing to labour scarcity or the cultivation of labour-intensity crops, late preparation, sowing, weeding or harvesting can have an adverse effect on yield. The management of labour, the farm equipment available, as well as the use of draught animals and mechanisation, greatly affect farm activities and the quality and quantity of production.

Farmers in Bangladesh are poor. Poverty stands in the way of their farming progress. Marginal income compels them to take a loan on farming. As a result, it creates a chronic crisis and it hampers them to nurture their plants on land. Therefore, they hardly purchase machinery and technological tools that are required to produce high yields. The table 2 illustrates that the table shows that $6 \%$ farmers have irrigation pump, power tiller $9 \%$, weeder $15 \%$, thresher $5 \%$, net and boat $21 \%$ and country plough $21 \%$. But the machines and irrigation are the types of technology that can increase yields. On the other hand, they have less number of ICT tools that can provide ideal conditions for high quality crops. The table 3 shows that only $20 \%$ farmers have radio, whereas $75 \%$ mobile and $62 \%$ television. On the other hand, only $11 \%$ farmers have computer and $15 \%$ motorcycle, but $65 \%$ farmers have a bicycle.

Education, age and gender are the factors associated with farming. The gender gap in the agricultural operation exists in Bangladesh and elsewhere. It is associated with assets, inputs, services, including land, livestock, labour, education, extension and financial services, and technology. The number of female famers is disproportionately lower than the male ones. Therefore, gender disparity in farm holding is severe in Bangladesh. So, agricultural sector in Bangladesh is traditionally marked by male domination as a rule of succession, the mode of production, the division of labour and the access to education whereas women are the pillar of the family and agricultural enterprises. In some cases, women play an important role in preharvest activities, whereas in most of the cases of post-harvest activities, women play an important role than the male farmers do. Yet, women in Bangladesh are not regarded as farmers as they do not possess the farm proprietorship. In the study, the percent of female farmers are found far less. Only 5\% of female farmers hold farm proprietorship. Age of a farmer reflects his/her activity and their ability to work in the field. It is an important factor as it affects their health and safety. This independent variable influences income, production and many other things from time to time. Different respondents belong to different age groups. The age range of the respondent farmers varies from 15 to 70 years. The age calculation in detail is shown in the table 4 that shows that only $2 \%$ farmers are in the age range of $20-30$ whereas $36 \%$ farmers are in 50-60 age range. In education, it is also a frustrating scene. Illiteracy grapples most of the ICT based activities owing. The recently engaged young farmers with standard education 
are now entering into farming and are more efficient in ICT equipments of farming. They possess higher education. Here it is shown in the table 5 showing that a good number of farmers $(25 \%)$ are illiterate, but farmers with higher education (MA) are less (1\%).

A large body of research has demonstrated that house $\neg$ hold-level motivations, cultural and social values, and socialization have a primary influence on farm structure, management, and adaptation (Gasson and Errington, 1993; Lobley and Potter, 2004; Salamon, 1992; Bennett, 1982). More studies have found social fulfillment through farm ing and ranching consistently ranks as a primary motiva $\neg$ tion to continue ranching despite low profits and devel $\neg$ opment pressure. All farmers must balance economic and non-economic goals, which have historically benefited ag $\neg$ riculture and ensured the persistence of family farms and ranches (Inwood, 2013). First Generation farmers are found to struggle to access capital, land, credit, and information (Mailfert, 2006). Yet, Barbieri and Mahoney (2009) found that younger farmers, especialᄀly those new to farming, are more entrepreneurial and willing to tolerate the risks associated with innovation be $\neg$ cause they were not restricted by pre $\neg$ vious investments in traditional farm-ing assets. Asfaw \& Admassie (2004) reported that it is not the conventional factor, but education contributes to agricultural production and national income. This is because information and knowledge are prerequisites for farmers to adopt technology, access input, change ways of doing things and market their produce (Chowa, Garforth, \& Cardey, 2012). Women tend to be the major players in the farm labour force engaged in production, harvesting and processing activities (Jafry, \& Sulaiman, 2013).The farm operator's age, family size and landholding size influence agricultural production and income. The age of the household head is a proxy variable for the farming experience of farm operators. Farmers are highly dependent on their previous knowledge of farm practices in cultivating different crops (Adomi, Ogbomo, \& Inoni, 2003). Hence, experienced farmers are expected to enhance the productivity of their holdings. However, it is not without limit as older farmers lack the required physical strength on the farm and lower the probability of technology.

\section{METHODS}

Farmers all over the country were the population of the study. The study was conducted on 820 farmers from seven administrative divisions of Bangladesh- Dhaka, Chittagong, Rajshahi, Khulna, Barisal, Rangpur and Sylhet and it covered almost 39 Districts (69.94\%). Areas range from South-east Rangamati to North-east Netrokona and South-west Satkhira to North-east Sylhet. Table 6 shows Sylhet Division is the highest responding area $21.34 \%$, Khulna $18.29 \%$, Chittagong, $7.32 \%$, Rajshahi and Rangpur (12.80\%), Dhaka 16.46\% and Barisal10.98\%. Few instruments for the data collection were employed in the study. The main instrument was taken as one set of questionnaire for the rice, vegetable and fish farmers. To consider total agriculture, rice, vegetables, fisheries and livestock sectors are given priority to distribute the questionnaire. Random sampling was used in the study. Eight hundred and twenty is the sample size of the present study. Formal and informal, semi-structured interviews were held to explore the views, experiences, beliefs and motivations of individual participants. The interview was conducted for finding answers to the main research questions of this study. The arrangement of interviews was assisted by the local farmers. Seven Focus Group Discussions (FGDs) were conducted for generating information on collective views and the meanings that lie behind those views. Extensive field visits in those areas were made. The data for the present study were collected during FebruaryDecember in 2014. All the questionnaires have been administered in the face-to-face sittings. While administering the questionnaire survey in different sites, the researcher collected the production and income information by using the recall method. The baseline time was calculated as 2012 and followup time as 2014. Income was the dependent variable, whereas famers, land, labour, gender etc. were independent variables. The data were analyzed with statistical inference. Statistical Package for Social Sciences (SPSS) was used to interpret the quantitative data. The multiple linear regression model was used to have an impact of independent variables on farm income.

\section{RESULT AND DISCUSSION}

The figure 1 shows that five agricultural activities are done by women. $42 \%$ of the women preserve seed, $19 \%$ rear poultry, $11 \%$ women rear livestock, $27 \%$ women process crops and $1 \%$ women sow seed. The figure 2 shows that $44 \%$ decision about the selection of nutritional vegetables comes from women, $32 \%$ for the healthcare of livestock, and $9 \%$ for fish variety, $5 \%$ for marketing and $10 \%$ for the selection of crop variety. The table 7 indicates that multiple linear regression model analysis shows the 
best in the sense of involving no multicollinearity. It shows that two independent variables have a correlation in excess of 0.80 .Through backward elimination and forward selection, fourteen explanatory variables were selected and their effect on the quantity of annual income behavior was determined.

The estimated multiple linear regression model for the quantity of annual income (Y) on fourteen explanatory variables such as gender (x1), Age of the farmers (x2), Years of schooling (x3), Service area (x4), Operational farm size (x5), Cowshed (x6), Electricity (x7), Radio (x8) Mobile phone (x9), Television (x10), Computer (x11), Bicycle (x12), Motorcycle (x13) and Sources of loan (x14) out of fourteen explanatory variables is as follows:

$\mathrm{Y}=-74313.32+119091.18 \mathrm{x} 1+4952.22 \times 2+10247.05$

$\mathrm{x}+349430.44 \times 4+39696.84 \times 5+198512.48 \times 6+105883.05 \times 7+129867.89 \times 8-$

$11643.85 \times 9+82978.19 \times 10+176839.60 \times 11+99416.89 \times 12+81427.43 \times 13+40736.15 \times 14$

This multiple linear regression model with fourteen explanatory variables has an R2 value of 0.438 which indicates that $43.8 \%$ of farmers' annual income can be explained by the combined effect of these fourteen variables by this model and the other 56.2 percent remained unexplained.

The F-statistic has numerical value 30.028 with an associated significance of 0.000 . So the null hypothesis is rejected and concludes that the regression model is well fitted (Table 7). Hence, the R2 value is significant at the 0.000 level. It is also revealed from the table that combined effect of all different explanatory variables. Gender (x1), age of the farmers (x2), years of schooling (x3), service area (x4), operational farm size (x5), cow-shed (x6), electricity (x7), radio (x8) mobile (x9), television (x10), computer (x11), bicycle (x12), motorcycle (x13) and sources of loan (x14) significantly contribute to the quantity of the annual income of the farmers in the manner described by the multiple linear regression equation.

To evaluate individual regression coefficients, t-statistic was carried out to test the hypothesis. The null hypothesis is that there is no linear relationship existing between explanatory variables (xi) and quantity of farmers' annual income (y). To justify the above argument on an empirical basis, it was found that $t$-value of gender is $t=4.42$ with associated level of significance 0.00 , and $t$-value for the age of the farmers is $t=4.86$ with a probability level of significance 0.00 . Some variables are associated with significance level and some are not. So there is evidence that among all the explanatory variables exist in linear relationship i.e. affect the quantity of the annual income of the farmers. Some semistructured interviews were conducted to gather detailed information about the variables influencing on farm income. The result of the interviews and FGDs was purely generalized and triangulated to possibly extend the data for supplementing the findings of the questionnaire survey.

Gender disparity in agriculture of Bangladesh is one of the major social impediments that affect farmers' production and income. About $99 \%$ of post-harvest agricultural activities is done by women in rural villages. After reaping, crops are ground, husked, dried up and stored by mainly women. Besides these, women have to preserve seed, process crops, sow seed, rear poultry and livestock. It is important to note that in enhancing farm income, the full participation of men and women is very important.

Gender, farmer's age, years of schooling, operational farm size, cow-shed, electricity, radio, mobile, television, computer are independent variables in the study. These items have impact on farmers' annual income. Except mobile phone, all other thirteen parameters have positive coefficients which revealed that for each explanatory variable a greater unit is associated with a higher level of quantity of the annual production and income of the farmers. This means that these variables have a positive impact on the quantity of the annual income of the farmers.

It is interestingly revealed that mobile phone has a negative sign. The result shows an inverse relationship between the using of mobile phone and the annual income of the farmers. It indicates that an increase in using mobile phone decreases the chances of farmers' annual income by about -11643.85 BDT (Lac). The reason of negative result echoes that a large number of farmers use mobile phone either for other reasons than in agricultural activities. Therefore, the inverse use of mobile phone has turned the result into negative. It is being affected for gender, age of the farmers, years of schooling, service area, operational farm size, cow-shed, electricity, radio television, computer, bicycle, motorcycle and sources of loan.

The focus of this study was to investigate socio-economic factors that affect farm production and income in Bangladesh. The study finds fragmentation to be a big factor. Farmers' landholding size was 
found to be too small to fulfill the annual food requirements of households. The research also finds that gender parity is severe in farming in Bangladesh. A multiple linear regression model used to identify the determinants of farm income implies that a unit increase of some variables increases the farm income of the farmers except mobile phone. The model results for income also indicated that land size, age, possession of tools etc. were found to be statistically significant.

\section{CONCLUSION}

The study examines certain socio-economic factors influencing agricultural production and income. Insufficient agricultural machinery and ICT tools that Bangladeshi farmers possess hamper their modern cultivation. Thus, the government should initiate and support mechanized farming. This will help improve the productivity and annual income of the farmers in Bangladesh. Gender disparity that was found to be a major impediment discourages the total labour necessary for farm production and income. Thus, gender balanced farming should be ensured to enhance agricultural production and income. The study reveals an intensively small farm holding among the study respondents. This small farm holding brings decrease in production. Therefore, small holding farms need to be intensified and diversified through acquiring adequate knowledge and information. Among all the variables, mobile was found to be an inverse relationship with agricultural production and income which indicates that mobile phone is not properly used in farming activities and this improper use of mobile phone decreases agricultural production and income. Therefore, proper dissemination of information for agricultural and rural communities is a crucial task. In this regard, mobile can be used properly to disseminate modern technology in farming activities. Moreover, proper attention could be paid to improve the information dissemination services for augmenting agricultural production and accelerating farm income.

\section{REFERENCES}

Abugamea, H. G. (2008). A Dynamic Analysis for Agricultural Production Determinants in Palestine: 1980-2003. International Conference on Applied Economics - ICOAE 2008.

Adomi, E. E., Ogbomo, M. O., \& Inoni, O. E. (2003). Gender factor in crop farmers' access to agricultural information in rural areas of Delta State, Nigeria. Library Review, 52, 388-393.

Anyanwu, O. S. (2009). Determinants of Aggregate Agricultural Productivity among food crop farmers in Rivers State, Nigeria. J. Vocational Education and Technology, 6 (1 \& 2).

Asfaw, A., \& Admassie, A. (2004). The role of education on the adoption of chemical fertilizer under different socio-economic environments in Ethiopia. Agricultural Economics, 30, 215-228.

BBS (1996). Statistical pocketbook of Bangladesh 1996, Bangladesh Bureau of Statistics (BBS), Planning Division, Ministry of Planning, Government of People's Republic of Bangladesh.

BBS (2009). Statistical Pocketbook of Bangladesh 2008, Bangladesh Bureau of Statistics (BBS), Planning Division, Ministry of Planning, Government of People's Republic of Bangladesh.

BBS (2016). Statistical pocketbook of Bangladesh 2015, Bangladesh Bureau of Statistics (BBS), Planning Division, Ministry of Planning, Government of People's Republic of Bangladesh.

BBS (2015). Yearbook of Agricultural Statistics 2012, Statistics and Information Division, Ministry of Planning, August, Government of the People's Republic of Bangladesh.

Bennett, J. (1982). Of time and enterprise North American family farm management in a context of resource marginality. Minneapolis: University of Minnesota Press.

Bruckner, M., LaFleur, M., \& Pitterle, I. (2017). The Impact of the technical revaluation on labour markets and income distribution, London.

Chowa, C., Garforth, C., \& Cardey, S. (2013). Farmer Experience of Pluralistic Agricultural Extension, Malawi. The Journal of Agricultural Education and Extension, 19, 147-166.

Das, S. (2016). Enhancing the Role of ICT in Disseminating Agricultural Information to Farmers in Bangladesh. An unpublished PhD dissertation, University of Dhaka, Bangladesh.

Gasson, R. \& Errington, A. (1993). The Farm Family Business. Wallingford, Oxon, UK, CABI.

Hasan, Md. N., Hossain, S. M., Islam, Md. R., \& Bari, Md. A. (2013).Trend in the availability of agricultural land in Bangladesh. Soil Resource Development Institute (SRDI), Dhaka.

Imahe, O. J. \& Alabi, R. A. (2005). The determinants of agricultural productivity in Nigeria.

ISSER (2013). The State of the Ghanaian Economy in 2012. Legon: Institute of Statistical, Social and Economic Research. 
Inwood, S. (2013). Social Forces and Cultural Factors Influencing Farm Transition. Choices, 28(2), 15.

Islam, S., \& Jamal, A. A. (2003). Banglapedia: National Encyclopedia of Bangladesh (IST ed.). Dhaka, Bangladesh: Asiatic Society of Bangladesh.

Jafry, T., \& Sulaiman, R. (2013). Gender-Sensitive Approaches to Extension Programme Design. The Journal of Agricultural Education and Extension, 19, 469-485.

Lobley, M. \& Potter, C. (2004). Agricultural change and restructuring: Recent evidence from a survey of agricultural households in England. Journal of Rural Studies, 20, 499-510.

Mailfert, K. (2006). New farmers and networks: how beginning farmers build social connections in France. Tijdschrift voor Economische en Sociale Geografie, 98(1), 21-31.

Moussa, B., Otoo, M., Fulton, J., \& Lowenberg-DeBoer, J. (2011). Effectiveness of Alternative Extension Methods through Radio Broadcasting in West Africa. The Journal of Agricultural Education and Extension, 17, 355-369.

Olujenyo, F. O. (2008). The Determinant of Agricultural Production and Profitability in Akoko Land, Ondo-State, Nigeria. Journal of Social Sciences, 4(1), 37-41.

Odhiambo, W., Nyangito, H. O. \& Nzuma, J. (2004). Sources and Determinants of Agricultural Growth and Productivity in Kenya. Kenya Institute for Public Policy Research and Analysis (KIPPRA), Discussion Paper No.34. Nairobi, Kenya.

Owuor, J. (1997). Determinants of Agricultural Productivity in Kenya. Retrieved on June 28, 2015, from www.fsg.afre.msu.edu./Kenya/detr_agprod.pdf

Salamon, S. (1992). Prairie patrimony: family, farming, and community in the Midwest: Chapel Hill: University of North Carolina Press.

Teryomenko, H. (2008). Farm Size and Determinants of Agricultural Productivity in Ukraine. Retrieved on June 28, 2015, from www.kse.org.ua/uploads/file/library/2008/batalina.pdf 
Table 1. Frequency distribution of farm category

\begin{tabular}{lcc}
\hline \multicolumn{1}{c}{ Farm Category } & No. & \% \\
\hline Landless & 39 & 5 \\
Marginal & 375 & 46 \\
Small & 330 & 40 \\
Medium & 68 & 8 \\
Large & 8 & 10 \\
\hline \multicolumn{1}{r}{ Total } & $\mathbf{8 2 0}$ & $\mathbf{1 0 0}$ \\
\hline
\end{tabular}

Table 2. Frequency distribution of machinery

\begin{tabular}{|c|c|c|}
\hline Machinery & Frequency & Percentage \\
\hline Irrigation Pump & 48 & 6 \\
\hline Power tiller & 75 & 9 \\
\hline Weeder & 131 & 16 \\
\hline Thresher & 41 & 5 \\
\hline Net & 172 & 21 \\
\hline Boat & 172 & 21 \\
\hline Country Plough & 172 & 21 \\
\hline Total & 820 & 100 \\
\hline
\end{tabular}

Source: (Author Survey 2013-2014)

Table 3. Frequency distribution of ICT tools

\begin{tabular}{lcccc}
\hline \multirow{2}{*}{ ICT Tools } & \multicolumn{2}{c}{ Yes } & \multicolumn{2}{c}{ No } \\
\cline { 2 - 5 } & Frequency & \% & Frequency & \% \\
\hline Radio & 165 & 20 & 665 & 80 \\
Mobile & 615 & 75 & 220 & 25 \\
Television & 508 & 62 & 312 & 38 \\
Computer & 90 & 11 & 730 & 89 \\
Bicycle & 535 & 65 & 285 & 35 \\
Motorcycle & 120 & 15 & 700 & 85 \\
\hline
\end{tabular}

Source: (Author Survey 2013-2014)

Table 4. Frequency distribution of farmers' age

\begin{tabular}{ccc}
\hline Age (in years) & No. & Percentage \\
\hline A (20-30) & 15 & 2 \\
B (30-40) & 270 & 33 \\
C (40-50) & 150 & 18 \\
D (50-60) & 295 & 36 \\
E (60-70) & 90 & 11 \\
\hline Total & $\mathbf{8 2 0}$ & $\mathbf{1 0 0}$ \\
\hline
\end{tabular}

Source: (Author Survey 2013-2014)

Table 5. Frequency distribution of farmers' education

\begin{tabular}{ccc}
\hline Education & No & Percentage \\
\hline A (Illiterate) & 206 & 25 \\
B (Primary) & 258 & 31 \\
C (Junior High School) & 184 & 22 \\
D (SSC) & 103 & 13 \\
E (College) & 61 & 7 \\
F (University) & 8 & 1 \\
\hline Total & $\mathbf{8 2 0}$ & $\mathbf{9 9}$
\end{tabular}

Source: (Author Survey 2013-2014)

Table 6. Frequency distribution of respondents

\begin{tabular}{ccc}
\hline Division & Frequency & Percentage \\
\hline Barisal & 90 & 10.98 \\
Chittagong & 60 & 7.32 \\
Dhaka & 135 & 16.46 \\
Khulna & 150 & 18.29 \\
Rajshahi & 105 & 12.80 \\
Rangpur & 105 & 12.80 \\
Sylhet & 175 & 21.34 \\
\hline Total & $\mathbf{8 2 0}$ & $\mathbf{1 0 0 . 0 0}$ \\
\hline
\end{tabular}

Source: (Author Survey 2013-2014) 
Table 7. Regression line of income on different independent variables

\begin{tabular}{|c|c|c|c|c|}
\hline \multirow{2}{*}{ Parameters } & \multicolumn{2}{|c|}{ Coefficients } & \multirow{2}{*}{ t-Statistic } & \multirow{2}{*}{ Sig. } \\
\hline & $\mathbf{B}$ & Std. Error & & \\
\hline (Constant) & -74313.32 & 93064.60 & -0.80 & 0.42 \\
\hline Gender (dummy: Female $=0$, Male $=1$ ) & 119091.18 & 26964.18 & 4.42 & 0.00 \\
\hline Age of the Farmer & 4952.22 & 1019.68 & 4.86 & 0.00 \\
\hline Years of Schooling & 10247.05 & 2630.09 & 3.90 & 0.00 \\
\hline Service area (dummy: $\mathrm{ICT}=0$, Non-ICT $=1$ ) & 49430.44 & 25909.21 & 1.91 & 0.06 \\
\hline Operational farm size (ha) & 39696.84 & 23061.18 & 1.72 & 0.09 \\
\hline Cowshed (dummy: Yes $=0, \mathrm{No}=1$ ) & 198512.48 & 23746.18 & 8.36 & 0.00 \\
\hline Electricity (dummy: Yes=1, No =0) & 105883.05 & 38808.10 & 2.73 & 0.01 \\
\hline Radio (dummy: Yes $=0, \mathrm{No}=1$ ) & 129867.89 & 21252.51 & 6.11 & 0.00 \\
\hline Mobile (dummy: Yes $=1$, No $=0$ ) & -11643.85 & 62046.91 & -0.19 & 0.85 \\
\hline Television (dummy: $\mathrm{Yes}=1, \mathrm{No}=0$ ) & 82978.19 & 27465.59 & 3.02 & 0.00 \\
\hline Computer (dummy: Yes $=1$, No $=0$ ) & 176839.60 & 22746.73 & 7.77 & 0.00 \\
\hline Bicycle (dummy: Yes=1, No =0) & 99416.89 & 18753.09 & 5.30 & 0.00 \\
\hline Motor Cycle (dummy: Yes=1, No =0) & 81427.43 & 22295.90 & 3.65 & 0.00 \\
\hline Sources of Loan (dummy: Bank $=1$, Otherwise $=0$ ) & 40736.15 & 23796.43 & 1.71 & 0.09 \\
\hline
\end{tabular}

$\mathrm{F}=30.028, \mathrm{df}=12, \mathrm{Sig}=0.000 ; \mathrm{R} 2=0.438$ and $\mathrm{Adj} \mathrm{R} 2=0.423$

Source: (Author Survey 2013-2014)

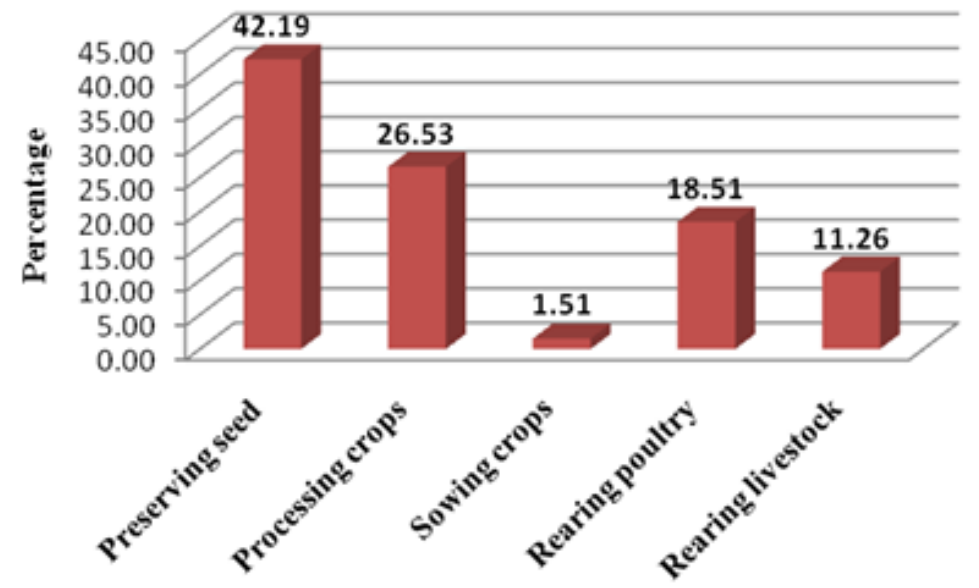

\section{Agricultural Works done by Woman}

Figure 1. Women involvement in agricultural works

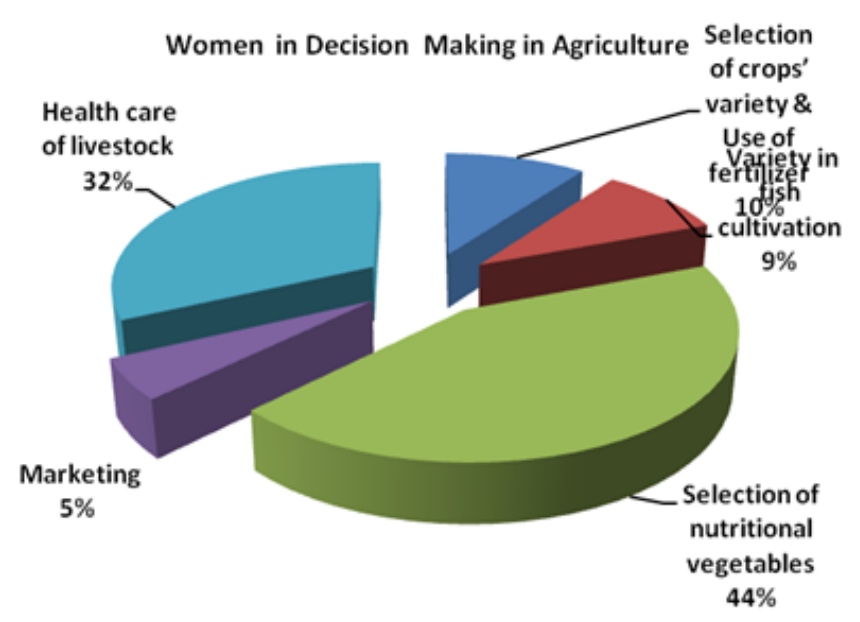

Figure 2. Women in decision making in agriculture 